\title{
Mental Hospitals in India in the 21st century: transformation and relevance
}

\author{
P. Murthy ${ }^{1}$, M. Isaac ${ }^{2 *}$ and H. Dabholkar ${ }^{3}$ \\ ${ }^{1}$ National Institute of Mental Health and Neuro Sciences, Bangalore, India \\ ${ }^{2}$ University of Western Australia and Fremantle Hospital, Australia \\ ${ }^{3}$ Parivartan, Satara, India
}

\begin{abstract}
Mental hospitals in India, as elsewhere in the world, have played an important role in the care of persons with mental illness. Since their inception, they have both been decried for gross violations of human rights and dignity as well as lauded as places of refuge and care for persons turned away by the communities. In a country where community interventions for mental health care are still fragmentary, the mental hospital still continues to be a relevant and legitimate locus of care along with other limited resources available for the care of persons with mental illness outside of the family. In India, positive changes in the infrastructure and resourcing of mental hospitals, reductions in involuntary admissions and improvements in facilities have largely occurred through judicial interventions. Recent pilot interventions for rehabilitation of long-stay patients point towards the need to develop rehabilitation and community facilities for persons with severe mental illness.
\end{abstract}

Key words: Community mental health, epidemiology, health service research, mental illness stigma, quality indicators.

\section{Introduction}

As is common in many other countries, the beginning of modern psychiatry in India was ushered in through the introduction of mental asylums during the colonial era. Starting with the first asylum in Calcutta in 1787 (Ernst, 1987), the growth of mental hospitals in India has been described in three phases (Sharma \& Chadda, 1996) - the first being the early development of private facilities that were later taken over by the State; the second where the institutions grew in number but functioned largely as centres of detention and the third, where the hospitals came under the control of the civil surgeons and later psychiatrists. More than a score of the mental hospitals presently functioning in India were established in the pre-independence era.

Mental hospitals in India have had their share of disrepute since their very existence. The general narrative of the mental hospital in India is not dissimilar to parallels across the world. While early reports are replete with accounts of high death rates, petty corruption, punishment and squalor, there is also the counter narrative of caring superintendents and healing environs (Ernst, 1987; Sarin et al. 2016). Notwithstanding these dichotomous descriptions, the general picture of the mental hospitals in the early 20th century was grim and disturbing. So much so, Edward Mapother's report in 1938 refers to overcrowding, indifference, desolation,

* Address for correspondence: M. Isaac, National Institute of Mental Health and Neuro Sciences, Bangalore, India.

(Email: mohan.isaac@uwa.edu.au) ugliness and corruption. Apart from a couple of exceptions (the European Hospital at Ranchi and the Mysore Mental Hospital), he rated the others on a 'scale of badness' (National Human Rights Commission, NHRC, 1999). Mapother made a dozen recommendations with respect to admissions, care in institutional facilities and training of the staff in mental health. Shortly after, Moore Taylor, the superintendent of the European mental hospital at Ranchi, and a member of the Bhore Committee (the Health Survey and Development Committee) surveyed 19 mental hospitals with bed strength of 10181 (Taylor, 1946). He commented that the hospitals were only designed for safe custody and detention rather than regard for curative treatment and suggested the modernisation of the hospitals. He emphasised the need for training and adequate staffing, conversion into teaching institutions and affiliation of the mental hospitals to medical colleges, a systematic and better conceived plan of 'work and diversional therapy', special supervised homes for the mentally ill requiring medical or nursing care, establishment of 'outdoor clinics', mental health programmes in detention facilities, integration of mental health with other medical specialties and engagement with the community, making people 'glad they can have what the institution has to offer' (NHRC, 1999). Taylor mentioned that 'it was a suitable time for Government to take account of stock, overhaul resources and re-chart the course for the next 30 years' (Taylor, 1946).

The next three to five decades witnessed at least four national meetings of superintendents of mental hospitals coming together to discuss the same issues over 
and over again (NHRC, 1999) - concerns about living conditions, poor hospital infrastructure and functioning, lack of trained staff, need for outpatient, emergency, day care and rehabilitation services, need for specialised services for children, alcohol and drug abuse and for the criminally mentally ill, need for community linkages, need to strengthen psychiatry training and a role for the mental hospitals in such training, mechanisms for internal and external monitoring and development of mental health services in the general hospitals. The enthusiasm and commitment of the medical superintendents was not in doubt. However, no one seemed to have the authority to implement these changes at a national level.

In a fairly unique development, the impetus for reform and transformation of mental hospitals in India was the entry of judicial interventions that changed the landscape of mental health care, particularly of mental hospitals in India.

\section{Judicial interventions: a replay}

Judicial intervention in mental health can be traced back initially as responses to public interest litigation (PIL) to the Supreme Court of India that occurred over the last three decades (NHRC, 2016). The first of these can be traced back to the 1980s, and concerned the 'inhuman treatment of inmates' of a protection home in Agra. This was followed by a slew of PILs concerning mentally ill prisoners languishing in jails, the state of the public Shahdara Mental Hospital in Delhi and the detention of abandoned children and those with mental retardation 'in jails for safe custody'. The responses from the Supreme Court included orders for monitoring of the home, direction to the NHRC to monitor specific mental hospitals, declaration of the keeping of mentally ill in jails as illegal and unconstitutional and against Articles 21 (protection of life and personal liberty) and 22 (protection against arrest and detention in certain cases) of the Indian constitution.

\section{National Human Rights Commission}

The NHRC's involvement began with the monitoring of the state mental hospitals at Agra, Ranchi and Gwalior in 1997, in a 'totally open and transparent and participatory style of monitoring the pace and progress of activities in the mental hospitals that it was initially assigned keeping the human rights dimension uppermost' (NHRC, 2016). In addition to such monitoring, the NHRC supported an initiative on quality assurance in mental health, which included an evaluation of the mental hospitals in the country through questionnaires and personal visits (NHRC, 1999, 2016). This evaluation, undertaken by the National Institute of Mental Health and Neuro Sciences (NIMHANS) was almost a throwback to 1938, when Edwin Mapother in his report on the needs of mental hospitals, observed scathingly that most of the hospitals as being 'desolate waste, based on the conception that the insane are indifferent to ugliness and are destructive'. The NIMHANS/NHRC Report (NHRC, 1999) showed gross deficiencies in physical structure and functioning of the hospitals. There were severe staff shortages and patients' rights were being violated. Most admissions were involuntary and occurred through the courts. Little occurred apart from medical management and psychosocial interventions were almost non-existent. The report argued for the urgent need to enhance human resources, as well as increase financial and other resources. It raised concerns that mental health services received the lowest priority in health care, which, in turn, also lacked adequate resources. The report argued for 'enlarging the scope of 'mental health services' by diversifying the services provided in the mental hospital and general hospital psychiatric facilities, developing community-based alternatives to hospitalisation, decentralisation of mental health care, development of a continuum of services for persons with chronic mental illnesses, mental health care in the least restrictive manner, community participation in policy and service development and inter-sectoral collaboration. It called for the transformation of mental hospitals to make them more therapeutic rather than custodial by increasing voluntary admissions, encouraging open wards and admissions with family members, development of services for the elderly, rehabilitation facilities for the long-stay patients, active out-patient and follow-up services, and engagement in community-based services.

The report envisaged that mental hospitals would remain 'an essential part of psychiatric services', along with general hospital psychiatric units, community-based mental health services, nongovernmental agency involvement, development of rehabilitation facilities, services for special populations such a children, the aged, the underprivileged, the rural and indigenous populations. It mentioned the important role of professional mental health bodies, the need for training and research in mental health and the need for periodical review of legal provisions. At that time, the Mental Health Act of 1987 and the Persons with Disabilities Act of 1995 had become operational (NHRC, 2016).

Although the NHRC Report of 1999 could be perceived as a 'defining moment' (Channabasavanna \& Murthy, 2004) in improving mental health care, the findings may have gathered dust but for the Erwadi 
tragedy, a fire which engulfed mentally ill persons who had been chained and kept in confinement in a faith-based institution in the southern state of Tamil Nadu in 2001. A PIL followed soon after. The apex court directed the central government to conduct a survey on an all-India basis to ascertain if the NHRC recommendations were being followed. The court directed states which did not have mental hospitals to set up mental hospitals to serve its constituents. As a result, new state psychiatric hospitals were set up in the states of Arunachal Pradesh, Bihar, Chattisgarh, Himachal Pradesh and Uttarakhand (NHRC, 2016). This may appear somewhat counterintuitive at a time when the focus globally is on developing community based services.

\section{The impact of monitoring}

Meanwhile, a review carried out by NIMHANS in 2008 on behalf of the NHRC (NHRC, 2008), a decade after the first comprehensive survey of the mental hospitals indicated positive trends, including a reduction in involuntary admissions, improvement in living conditions, relatively better engagement with the community and non-government organisations (NGOs) and improved budgetary allocations. However, shortage of human resources, inadequate psychosocial interventions, operational 'closed ward' structures and attitudes and lack of mental health training courses were persisting lacunae. One striking observation was that hospitals that were being monitored by the special rapporteurs of the NHRC, with regular visits, negotiation with the state administration and active engagement with the hospital administrators were likely to have outperformed hospitals that did not have such monitoring.

\section{Rewinding to developments in community mental health}

Meanwhile, efforts to develop community mental health services were initiated with the National Mental Health Programme (NMHP), launched in 1982 and re-strategised in 2003 (DGHS 2004).

However, the pace has been slow with little progress made in developing community-based services (NHRC, 2016).This has led to a relative stasis in substantial improvements in mental health care services.

\section{Limited impact and road blocks}

In 2013, the NHRC petitioned the Supreme Court once again seeking its directions to deal with and overcome the deficiencies in the mental health care in the system still persisting despite its interventions (NHRC, 2016). The central government also expressed its limitations in the further improvement in mental health care, as health was a state subject and not directly under its jurisdiction.

\section{Fast-forward again to judicial interventions}

There has been a bustle of activities in the country at the instance of the Supreme Court in the last 2 years. States were directed to fill out questionnaires (prepared by NIMHANS and submitted by the NHRC and) on both the problem of mental illness and responses in terms of service delivery through specialised psychiatric facilities, medical colleges and general hospitals, non-governmental organisations and the district mental health programme (NHRC, 2016). A four-member Technical Committee (TC) comprising three psychiatrists was constituted by the NHRC to appraise the apex court of the deficiencies in mental health care in the States. The NHRC also identified special rapporteurs to visit different states and evaluate first-hand the quality of mental health care. The apex court also instructed the central Health Secretary to arrange for an inspection of the psychiatric institutions, which were ultimately visited by a team that included the central Joint Secretary of Health, the State Health Secretary, the State Human Rights Commission, the State Mental Health Authority and two eminent psychiatrists. For some of the hospitals, this was the first gaze they had received from such an eminent body (NHRC, 2016).

\section{Report of the TC of the NHRC}

The TC consolidated all these findings in its report to the NHRC (NHRC, 2016) and the Supreme Court. The findings were startling. Most States and Union Territories neither had a realistic idea of the burden of mental illness, nor a documentation of the resources that were available. The report observed, 'One can assume that the priority to mental health is low. But if a directive from the Apex Court in the country and a sworn affidavit can still not shake off the lethargy and swing the system into action, one wonders what else can'.

Returning to the theme of the mental hospitals, a sizeable proportion of existing hospital beds (18307) lie in the 47 government psychiatric institutions in the country (NHRC, 2016). Infrastructure has improved across the hospitals. The Inspection Committee of the government noted massive transformations in many of the institutions, with adequate 
drugs, food, hygiene and living facilities (NHRC, 2016). The hospitals had active outpatient services. About a third had developed specialised services for children, substance use disorders and the elderly. Problems that were persistent included a shortage of human resources, varying levels of recreation and rehabilitation, variation in oversight from bodies like the relevant state mental health authority and human rights commission.

While changes in infrastructure and functioning are marked in most institutions, hospitals in a few states continue to have the same old problems. A report by the Human Rights Watch (2014) raises concerns of rights violations against women and prompted the National Commission for Women to undertake a study on gender issues related to the mentally ill in institutions (NCW, 2016) and the major problem of long-stay destitute patients.

In many ways, the Inspection Committee's recommendations resonate with those made earlier by Mapother and Taylor in the last century and more recently in the reports of the NHRC - improving human resources, academic training, improved medical care of the mentally ill, specialised ward for children, elderly, addiction, mentally ill prisoners, rehabilitation and reintegration, setting up of half-way homes and alternative residential facilities for patients who cannot return to families, linkages with the DMHP. Other recommendations include a more prominent display of patient rights in the hospitals, availability of anaesthetists for modified electroconvulsive therapy (which continues to be an accepted treatment in many facilities), proper maintenance of records, monitoring and oversight.

Rehabilitation of the chronically mentally ill continues to be an area of serious concern in India. Many of the chronically mentally ill in India, both in institutional care and those living with families have never received the benefits of rehabilitation and the chance to realise their potential, despite recovery from their psychiatric illness. The engagement with non-governmental organisations has helped to some extent in the rehabilitation of select long-stay patients, although long-term outcomes are still being debated. It would be worthwhile to highlight a couple of innovations focusing on reduction in hospital long-stay and rehabilitation. One such effort occurred in the Hospital for Mental Health in Gujarat, which demonstrated a significant reduction in long-stay patient over the previous decade. The success was attributed to making medications available, emphasising the short nature of admission, greater utilisation of open ward facilities where a family member stayed with the patient, family and carer self-help groups, better awareness to families, development of outreach services, training of staff in rehabilitation, involvement of family members in rehabilitation and the strengthening of NGO linkages (NHRC, 2016). Another innovation is the INCENSE programme that is featured below (Tata Trusts, 2015).

The integrated care for the needs of vulnerable persons with severe mental disorders (INCENSE) programme

The INCENSE programme has piloted a multi-component reform methodology in collaboration with two large mental hospitals in India - the Regional Mental Hospital $(\mathrm{RMH})$ at Pune in Western India and the Lokopriya Gopinath Bordoloi Regional Institute of Mental Health (LGBRIMH) at Tezpur in Northeastern India. The primary vehicle for the programme implementation was a collaborative partnership between the hospitals and two NGOs - Parivartan and Sangath.

The development and piloting of an innovative method of mental hospital reform through a collaborative network of multi-sectoral partners working together with mental hospitals to deliver locally relevant, humane, comprehensive, integrated and recovery-oriented care for highly vulnerable people with severe mental disorders (SMDs). Three types of participants were included: those living within hospitals for more than 12 months; homeless patients in predefined catchment area around the hospital; those residing in their homes in the vicinity of hospitals but without access to appropriate care. Key gaps that emerged from baseline situation analysis included the lack of community housing options, entry and exit difficulties into hospitals for homeless persons with SMDs and the absence of community based care to ensure continuity of services.

The INCENSE intervention had three broad components. The first included engagement with the mental hospitals for implementing systemic changes. The second included working with vulnerable individuals and their families for promoting their recovery. The third included the engagement of multi-sectoral partners to support the economic and social inclusion of persons with SMDs and their families.

Specific components of interventions addressed:

- Long-stay patients with SMDs: Structured psychosocial intervention to improve their individual functioning, access to meaningful work and recreational options and facilitate their exit to supported community living and working.

- Homeless patients with SMD: Identification, engagement, acute treatment in the hospitals and then relocation back to their families or to intermediate supported housing facilities for preparation towards independent living in the community.

- Persons with SMD living with their families: An additional collaborative care-based community intervention was provided in a defined catchment area 
at Tezpur and Pune with the hospitals continuing to provide necessary medical care.

These interventions were delivered by both hospital staff and by the programme team consisting of lay recovery support workers trained and supervised by specialists; the programme teams at the sites took the lead in identifying and networking with other local partners.

As a result, care pathways across the hospital and community were developed and included the establishment of a recovery oriented ward, long-stay home, supported housing; development of a service delivery system for the homeless patients; job placement of persons with SMDs and the restoration of basic citizenship entitlements. In addition, the intervention led to the development of a vibrant network of local and regional partners allied to the programme leading to opening up of multiple employment and meaningful rehabilitation opportunities. It also led to the inclusion and enabled participation of peers and family caregivers in the delivery of interventions.

While the mental hospitals reforms process has had two main approaches - deinstitutionalisation or conversion into training and education centres of excellence for improving services, the INCENSE programme introduces a third alternative framework and methodology of institutional reforms.

Overall, the implementation of INCENSE model has been feasible and acceptable and the potentially scalable components of INCENSE model are:

(1) Development of alternative housing options for persons with SMDs in mental hospitals like recovery oriented long-stay wards and supported community facilities.

(2) Development of community-based rehabilitation services along with a specific employment focused intervention.

(3) Development of services for homeless persons with mental illness as part of the mental hospital service delivery system.

(4) Packages of care for individual person-oriented care, recovery-oriented ward management, securing citizenship rights and the development of peer and care giver networks.

In the next phase, the INCENSE programme aims to scale up above-mentioned components of the model in collaboration with other mental hospitals in India and other LMICs.

\section{Road map nebulous}

Despite the overhaul of the mental hospitals and nearly three decades after the launching of the NMHP in India, a recently introduced The National Mental Health Policy (2014), a rights-based Mental Health Care Bill to replace the Mental Health Act of 1987 recently approved by the upper house of Parliament (Rajya Sabha) and a UNCRPD- compliant Persons with Disabilities Bill introduced to Parliament in 2015, the roadmap for mental health care still remains nebulous.

\section{Polarised positions}

Polarised positions regarding what should comprise the mental health landscape has not helped the cause. Among the many polarised positions in mental health care, prominent are those of service users $v$. service providers, public $v$. private sector, the health $v$. the social sector, and most importantly, community care $v$. care in institutions. Proponents of community care models decry the spending of resources on psychiatric institutions. Those sceptic of existing community care models believe that good psychiatric institutions are a legitimate shelter and diminishing their relevance will lead to other problems such as trans-institutionalisation.

This debate is not unique to India. In the USA as elsewhere, 'eliminating state hospitals (about 200 still exist) remains a goal despite the enduring importance of the services they provide' (Fisher et al. 2009). In the UK, people in crisis unable to find a hospital bed anywhere near home, long-waiting times for inpatient and community mental health team appointments and increasing suicide rates are some of the many challenges that mental health care faces (The Guardian, 2016).

\section{The mental hospital in perspective}

In a country like India, where community care is virtually negligible, integration of mental health care into general health care is an unfulfilled dream and private care is expensive, unaffordable by many and impoverishing for most, the continuing relevance of the mental hospital as a place of treatment and refuge for many persons with serious mental illnesses who might otherwise have been abandoned by helpless or uncaring families, died due to neglect or self-harm is apparent. While there are many contentious issues such as opening new state mental hospitals or converting them into highly specialised mental health and neuroscience institutes, areas of relatively greater agreement are to make these institutions more open in functioning, have trained and sensitive health care providers, focus on rehabilitation, engage more with the community and develop capacity for training and research.

\section{Acknowledgments}

None.

\section{Financial Support}

Tata Trust has supported the INCENSE programme. 


\section{Conflict of Interest}

The authors declare no competing interests.

\section{References}

Channabasavanna SM, Murthy P (2004). The National Human Rights Commission Report 1999: a defining moment. In Mental Health - An Indian Perspective 1946-2003. (ed. SP Agarwal), pp. 108-112. Elsevier: New Delhi. ISBN 81-8147-195-4.

Directorate General of Health Services (DGHS), MOHFW, Govt of India (2004). Mental Health-An Indian Perspective 1946-2003. (ed. SP Agarwal). Elsevier: New Delhi. ISBN 81-8147-195-4.

Ernst W (1987). The establishment of 'Native Lunatic Asylums' in early nineteenth century British India. In Studies on Indian Medical History (ed. GJ Meulenbeld and D Wujastyk), pp. 169-204. Egbert Forsten: Gronningen.

Fisher WH, Geller JL, Pandiani JA (2009). The changing role of the state psychiatric hospital. Health Affairs 28, 676-684.

Human Rights Watch (2014). Treated worse than animals. Abuses against girls with psychosocial or intellectual disabilities in institutions in India. Retrieved from hrw.org/ report/2014/12/03/treated-worse-animals/abuses-againstwomen-and-girls-psychosocial-or-intellectual.

National Commission for Women (2016). Addressing concerns of women admitted to mental hospitals: an indepth analysis. (ed. P Murthy, MN Kumar, P Chandra, $\mathrm{S}$ Bharath, $\mathrm{S}$ Badamath et al.). National Commission for Women: New Delhi. http://ncw.nic.in/pdfReports/ Addressing_concerns_of_women_admitted_to_
psychiatric_institutions_in_INDIA_An_in-depth_analysis. pdf

National Human Rights Commission (1999). Quality assurance in mental health. (ed. SM Channabasavanna, M Isaac, CR Chandrashekar, M Varghese, P Murthy, K Rao, K Reddamma, K Sekar, S Shetty and T Murali). NHRC: New Delhi.

National Human Rights Commission (2008). Mental health care and human rights. (ed. DN Nagaraja and P Murthy). NHRC: New Delhi.

National Human Rights Commission (2016). Report of the Technical Committee on mental health. (ed. P Murthy, S Kumar, N Desai and BK Teja). http://nhrc.nic.in/ Documents/Mental_Health_report_vol_I_10_06_2016.pdf

Sharma S, Chadda R (1996). Mental Hospitals in India. Current Status and Role in Mental Health Care. Institute of Human Behaviour and Allied Sciences: New Delhi.

Sarin A, Jain S, Murthy P (2016). More than Brick and Mortar. Reconstructing Histories of Mental Hospitals in India. National Institute of Mental Health and Neuro Sciences: Bangalore.

Tata Trusts (2015). The INCENSE Program. Grant completion report. Tata Trusts: Mumbai.

Taylor Col. M (1946). Report of the Health Survey and Development Committee, Vol. 3. Government of India Press: Simla.

The National Mental Health Policy (2014). National Mental Health Policy. New pathways, new hope. Ministry of Health and Family Welfare, Government of India. http://www. mohfw.nic.in/showfile.php?lid=2965

The Guardian (2016). Spike in mental health deaths shows the NHS is struggling to cope. http://www.theguardian. com/society/2016/jan/26/rise-mental-health-patient-deathsnhs-struggling-to-cope 